\title{
A relação interfederativa e a integralidade no subsistema de saúde indígena: uma história fragmentada
}

\author{
The interfederative relations and integrality in the indigenous health \\ care system: a fragmented history
}

Nayara Scalco', Fernando Aith², Marilia Louvison²

DOI: 10.1590/0103-1104202012601

\begin{abstract}
RESUMO A Constituição Federal estabelece a saúde como direito de todos e dever do Estado. Os povos indígenas obtiveram importante avanço para a garantia desse direito com a criação do Subsistema de Atenção à Saúde Indígena (Sasi) (Lei n ${ }^{\circ}$ 9.836/1999). Passados vinte anos desse marco legal, este artigo visa a identificar de que forma o Estado brasileiro organiza o Sasi e as pactuações de referências e contrarreferências; analisar as lacunas existentes e os principais desafios para a proteção do direito à saúde indígena no Brasil. Foi utilizada a metodologia qualitativa, com diversas fontes e materiais: identificação da legislação aplicável, análise documental da legislação selecionada e 24 entrevistas em profundidade com indígenas, gestores, indigenistas e representante do Ministério Público Federal. Os resultados demonstram que a fragmentação e a complexidade normativa dificultam a execução das políticas que buscam garantir a integralidade da assistência à saúde indígena. A gestão federal e a territorialização dos Distritos Sanitários Especiais Indígenas são especificidades que impactam na articulação federativa. Assim, embora tenham se verificado progressos no reconhecimento legal do direito dos povos indígenas à saúde, mostram-se fundamentais o aperfeiçoamento da legislação e o comprometimento dos diferentes gestores, visando a avanços e compromissos na garantia do acesso universal com equidade aos povos indígenas.
\end{abstract}

PALAVRAS-CHAVE Saúde de populações indígenas. Sistema Único de Saúde. Gestão em saúde. Integralidade em saúde. Legislação como assunto.

1 Secretaria de Estado da Saúde de São Paulo, Instituto de Saúde - São Paulo (SP), Brasil nayarascalco@gmail.com

2 Universidade de São Paulo (USP) - São Paulo (SP), Brasil.

ABSTRACT The Federal Constitution establishes health as social citizenship right under the responsibility of the State. The indigenous peoples had an important achievement to assure this right to health with Indigenous Health Care System (Sasi) (Law 9.836/1999). Twenty years after this legal framework, this article aims to identify how the Brazilian State organizes the Sasi and the reference and counter-referral agreements; analyze the existing gaps and the main challenges for the protection of the right to indigenous health in Brazil. The qualitative methodology was used, with several sources and materials: documental analysis of legislations and 24 in-depth interviews with Indigenous Peoples, managers, indigenists and Federal Prosecution Service. The results demonstrate that a normative fragmentation and the complexity hinder the implementation of the policies that should assure the integrality of the indigenous health assistance. The federal management and territorialization of the Special Indigenous Health Districts are specificities that also impact in the federative articulation. Therefore, even though progress has taken place legally recognizing health as indigenous right, it is still fundamental to improve the legislation to advance in compromises that assure health as a right with equity to indigenous populations.

KEYWORDS Health of indigenous peoples. Unified Health System. Health management. Integrality in health. Legislation as topic. 


\section{Introdução}

A luta dos povos indígenas conquistou há vinte anos a estruturação do Subsistema de Atenção à Saúde Indígena (Sasi). Entretanto, sua implantação efetiva enfrenta, até os dias atuais, inúmeros desafios que colocam em risco a vida dos povos originários.

As mobilizações sociais que se originaram no processo de redemocratização do Brasil, principalmente na década de 1970, também foram espaços para o movimento indígena reivindicar seus direitos. Os 305 povos indígenas que estão hoje distribuídos pelo território brasileiro ${ }^{1}$ conquistaram o direito, nos termos dos artigos 231 e 232 da Constituição Federal (CF) de 1988, de reconhecimento de suas práticas culturais, $\mathrm{o}$ que inclui suas medicinas ${ }^{2}$. Esse é um importante marco na política indigenista, que até então visava à integração desses povos, e, neste momento, passa a reconhecer sua identidade autodeclarada e a considerar o seu direito ao território pela sua presença ancestral ${ }^{3}$.

Lideranças indígenas que estavam mobilizadas para a garantia da demarcação de suas terras reconheceram a necessidade de uma política específica, com legislações claras, que estendesse o direito de acesso à saúde de qualidade a seus povos. Ocupando o espaço na VIII Conferência Nacional de Saúde (CNS) e com a organização de duas Conferências Nacionais de Saúde Indígena (CNSI), em 1986 e 1993, indígenas, profissionais e acadêmicos da área produziram relatórios que explicitaram ao governo brasileiro o que consideravam as diretrizes primordiais para a proteção da saúde indígena ${ }^{4,5}$, que se traduziram no Sasi, criado pela Lei no ${ }^{9} .836 / 1999$, que acrescentou o Capítulo V à Lei no 8.080/19906.

As decisões relacionadas às políticas públicas, no Estado Democrático de Direito, são traduzidas, fundamentalmente, por normas jurídicas constitucionais, legais e infralegais, que sintetizam a vontade estatal e orientam gestores e sociedade em suas ações. No Brasil, que se organiza política e territorialmente como uma Federação, compartilhando a legitimidade e as decisões coletivas entre os três níveis de governo (federal, estadual e municipal) ${ }^{7}$, a responsabilidade por cuidar da saúde, ou seja, executar a política de saúde, é dada solidariamente às três esferas.

$\mathrm{A} \mathrm{CF}$ e as Leis $\mathrm{n}^{\circ} 8.080 / 1990$ e $\mathrm{n}^{\circ}$ 8.142/1990 destacam que o Sistema Único de Saúde (SUS) tem como princípios básicos: a universalidade de acesso aos serviços de saúde em todos os níveis de atenção; a integralidade da assistência; a preservação da autonomia das pessoas na defesa de sua integridade física e moral; a descentralização político-administrativa; e a participação da comunidade ${ }^{6,8}$.

O Sasi, sob responsabilidade do governo federal, foi instituído para organizar a Atenção Básica (AB) de forma diferenciada dentro das aldeias indígenas, com a participação dos povos originários nos momentos decisórios ${ }^{9}$. Nesse sentido, foram criados 34 Distritos Sanitários Especiais Indígenas (DSEI), com seus respectivos Conselhos Distritais de Saúde Indígena (Condisi), além de Conselhos Locais ${ }^{10}$.

A construção política do Sasi resgata e assegura o direito constitucional à saúde, reconhecendo o direito dos indígenas às suas cosmovisões. Como discute Santos ${ }^{11(56)}$, que relaciona a dualidade entre o reconhecimento da igualdade e da diferença, o princípio da equidade é estrutural no SUS, sendo especialmente sensível para a discussão da política de saúde indígena. Esse princípio estabelece que

As pessoas e os grupos sociais têm o direito a ser iguais quando a diferença os inferioriza, e o direito a ser diferentes quando a igualdade os descaracteriza.

A equidade, entendida como um fator para a justiça social, considera o contexto de desigualdades e diversidade em que se insere o SUS, fortalecendo o protagonismo dos cidadãos em um sistema democrático ${ }^{\mathbf{1 2}}$. Embora as políticas de saúde devam ser afirmativas para a promoção do princípio da equidade, principalmente quando se trata da atenção à saúde dos povos indígenas, a implementação de tais políticas 
ainda enfrenta muitos desafios. O agronegócio, destaque do projeto de desenvolvimento econômico adotado pelo governo brasileiro, é um dos principais adversários do direito à autodeterminação dos povos indígenas ${ }^{13}$.

Os diversos impasses nas demarcações de terras indígenas, a crescente violência contra esses povos ${ }^{\mathbf{1 4}}$, a violação de tratados internacionais e da própria CF com propostas de novas legislações que enfraquecem o direito dos indígenas são considerados grandes entraves para uma saúde de qualidade desses povos. A íntima ligação dos povos indígenas com suas terras históricas é apontada pela União Nacional Indígena como imprescindível para a garantia de saúde desde a I CNSI ${ }^{15}$ quando afirma que:

a) A saúde das populações indígenas é resultante da interação de alguns elementos fundamentais: acesso à posse da terra; grau de contato com a sociedade nacional; liberdade para viver a sua singularidade (padrões alimentares, de educação, de moradia e de trabalho); acesso à vacinação e serviços de saúde ${ }^{\mathbf{1 5 ( 8 )}}$

Passados mais de 30 anos desde o reconhecimento dos direitos dos povos originários na $\mathrm{CF}$, o presente artigo visa a identificar de que forma o Estado brasileiro organiza o Sasi e as pactuações de referências e contrarreferências no sentido de analisar as lacunas existentes e os principais desafios para a proteção do direito à saúde indígena no Brasil.

\section{Metodologia}

A pesquisa utilizou a metodologia qualitativa por meio de coleta, organização e análise de documentos legais, bem como por meio da realização de entrevistas em profundidade ${ }^{16}$.

A seleção dos textos jurídicos foi realizada até janeiro de 2018 em pesquisa na base de dados Saúde Legis, que reúne as legislações referentes ao SUS na página de internet do Ministério da Saúde (MS).
A pesquisa buscou identificar normas por meio dos descritores 'saúde indígena', 'indígena' e 'subsistema de atenção à saúde indígena'. Dos resultados obtidos, foram selecionadas, após análise preliminar dos textos, as normativas sobre o Sasi, todas as publicações de origem da Secretaria Especial de Saúde Indígena (Sesai), as normas de organização do SUS e as normas que faziam referência às políticas prioritárias que organizam as redes de saúde no SUS. Não foram selecionadas neste estudo as normas infralegais que não são específicas do tema e as normativas da Sesai que tratavam de designações, licitações e assuntos gerenciais.

As entrevistas foram realizadas no primeiro semestre de 2017 com 11 indígenas de nove estados, que localizam-se nas cinco regiões do País; quatro indigenistas que atuam, principalmente, nas regiões Norte, Centro-Oeste, Sul e Sudeste; quatro gestores federais do Sasi; dois gestores estaduais das regiões Nordeste e Sul; dois gestores municipais da região Sudeste e um representante do Ministério Público Federal (MPF), escolhidos a partir de informantes-chave, por terem atuado no processo de construção da política de saúde indígena. Essas entrevistas foram conduzidas para permitir que os entrevistados falassem livremente sobre os temas que eram apresentados $^{16}$. São eles: contexto pessoal de sua inserção no tema; compreensão sobre a participação indígena na política de saúde e formas de participação indígena no Sasi; expectativas e avaliação da Política Nacional de Atenção à Saúde dos Povos Indígenas (PNASPI); e aproximações e distanciamentos entre SUS, Sasi e medicinas indígenas.

O material foi exaustivamente lido e escutado, para que fosse possível identificar as questões colocadas, buscando fazer emergirem os diversos conhecimentos, não os colocando em conflito, mas reconhecendo que cada um tem seu lugar de fala.

A pesquisa seguiu todas as recomendações da Comissão Nacional de Ética em Pesquisa, sendo aprovada no parecer 1.766.478. 
Considerando as características dos grupos de entrevistados, optou-se pela não identificação dos entrevistados da gestão, indigenistas e MPF, e pela identificação dos indígenas pela etnia e pela sigla do seu estado de origem.

\section{Resultado e discussão}

Foram identificadas oito normas estruturais do Sasi anteriores a Sesai, 373 portarias e uma resolução publicadas pela Sesai desde sua criação até dezembro de 2017, bem como 20 leis estruturantes do SUS e normas organizacionais da atenção à saúde. Dos textos encontrados, foram selecionados, segundo os critérios listados na metodologia, 34 textos jurídicos, sendo: três leis, dois decretos, 22 portarias do MS, uma resolução da Comissão Intergestores Tripartite e seis portarias de consolidação, que revogaram 10 das 22 portarias inicialmente encontradas. $\mathrm{O}$ quadro 1 detalha as normas selecionadas especificando autor, tipo de texto, número, descrição e situação da norma.

Quadro 1. Relação e descrição dos textos jurídicos sobre o direito à saúde selecionados e analisados

\begin{tabular}{|c|c|c|c|c|c|}
\hline Autor & Tipo de Texto & № & $\begin{array}{l}\text { Data de } \\
\text { Assinatura }\end{array}$ & Descrição da Norma & Situação Atual \\
\hline Brasil & Lei & 8.080 & 19/09/1990 & $\begin{array}{l}\text { Regulamenta o Sistema Único de Saúde (SUS) e estabelece suas } \\
\text { diretrizes e princípios. }\end{array}$ & Vigente \\
\hline Brasil & Lei & 8.142 & 28/12/1990 & Regulamenta a participação social no SUS. & Vigente \\
\hline Brasil & Decreto & 3.156 & 27/08/1999 & $\begin{array}{l}\text { Estabelece as condições para a prestação de assistência à saúde dos } \\
\text { povos indígenas pelo Ministério da Saúde. }\end{array}$ & Não localizada \\
\hline Brasil & Lei & 9.836 & 23/09/1999 & $\begin{array}{l}\text { Estabelece o Subsistema de Atenção à Saúde Indígena (Sasi), que } \\
\text { deve considerar o contexto intercultural, com gestão federal e com- } \\
\text { plementariedade de estados e municípios. }\end{array}$ & Vigente \\
\hline $\mathrm{MS} / \mathrm{GM}$ & Portaria & 254 & $31 / 01 / 2002$ & $\begin{array}{l}\text { Aprova a Política Nacional de Atenção à Saúde dos Povos Indígenas } \\
\text { (PNASPI). }\end{array}$ & $\begin{array}{l}\text { Revogada pela Con- } \\
\text { solidação no 2/2017 }\end{array}$ \\
\hline MS/GM & Portaria & 70 & 20/01/2004 & Aprova as Diretrizes da Gestão da PNASPI. & $\begin{array}{l}\text { Revogada pela Con- } \\
\text { solidação no } 2 / 2017\end{array}$ \\
\hline$M S / G M$ & Portaria & 644 & $27 / 03 / 2006$ & $\begin{array}{l}\text { Institui o Fórum Permanente de Presidentes dos Conselhos Distritais } \\
\text { de Saúde Indígena. }\end{array}$ & $\begin{array}{l}\text { Revogada pela Con- } \\
\text { solidação no } 4 / 2017\end{array}$ \\
\hline $\mathrm{MS} / \mathrm{GM}$ & Portaria & 204 & 29/01/2007 & $\begin{array}{l}\text { Regulamenta o financiamento e a transferência dos recursos fede- } \\
\text { rais para as ações e os serviços de saúde. }\end{array}$ & $\begin{array}{l}\text { Revogada pela Con- } \\
\text { solidação no } 6 / 2017\end{array}$ \\
\hline $\mathrm{MS} / \mathrm{GM}$ & Portaria & 2.759 & $25 / 10 / 2007$ & $\begin{array}{l}\text { Estabelece diretrizes gerais para a Política de Atenção Integral à } \\
\text { Saúde Mental das Populações Indígenas. }\end{array}$ & $\begin{array}{l}\text { Revogada pela Con- } \\
\text { solidação no 2/2017 }\end{array}$ \\
\hline $\mathrm{MS} / \mathrm{GM}$ & Portaria & 2.656 & $17 / 10 / 2007$ & $\begin{array}{l}\text { Dispõe sobre as responsabilidades na prestação da atenção à saúde } \\
\text { dos povos indígenas e regulamentação dos incentivos de atenção } \\
\text { básica (IAB-PI) e especializada aos povos indígenas (IAE-PI). }\end{array}$ & $\begin{array}{l}\text { Revogada pela Con- } \\
\text { solidação no 6/2017 }\end{array}$ \\
\hline Brasil & Decreto & 7.508 & 28/06/2011 & $\begin{array}{l}\text { Regulamenta a Lei no 8080, o planejamento da saúde, a assistência } \\
\text { à saúde e a articulação interfederativa. }\end{array}$ & Vigente \\
\hline $\mathrm{MS} / \mathrm{GM}$ & Portaria & 475 & $16 / 03 / 2011$ & $\begin{array}{l}\text { Estabelece a autonomia sanitária do Distrito Sanitário Especial } \\
\text { Indígena. }\end{array}$ & Vigente \\
\hline $\mathrm{MS} / \mathrm{GM}$ & Portaria & 3.088 & 23/12/2011 & Institui a Rede de Atenção Psicossocial. & $\begin{array}{l}\text { Revogada pela Con- } \\
\text { solidação no 3/2017 }\end{array}$ \\
\hline $\mathrm{MS} / \mathrm{GM}$ & Portaria & 755 & $18 / 04 / 2012$ & $\begin{array}{l}\text { Dispõe sobre a organização do controle social no Subsistema de } \\
\text { Atenção à Saúde Indígena. }\end{array}$ & $\begin{array}{l}\text { Revogada pela Con- } \\
\text { solidação no 4/2017 }\end{array}$ \\
\hline $\mathrm{MS} / \mathrm{GM}$ & Portaria & 2.012 & 14/09/2012 & Extingue o $\mid \mathrm{AB}-\mathrm{PI}$. & $\begin{array}{l}\text { Revogada pela Con- } \\
\text { solidação no } 6 / 2017\end{array}$ \\
\hline
\end{tabular}


Quadro 1. (cont.)

\begin{tabular}{|c|c|c|c|c|c|}
\hline Autor & Tipo de Texto & № & $\begin{array}{l}\text { Data de } \\
\text { Assinatura }\end{array}$ & Descrição da Norma & Situação Atual \\
\hline $\begin{array}{l}\text { MS/ } \\
\text { Sesai }\end{array}$ & Portaria & 34 & 24/05/2013 & Institui o Comitê de Educação Permanente no âmbito do Sasi. & Vigente \\
\hline $\begin{array}{l}\text { MS/ } \\
\text { Sesai }\end{array}$ & Portaria & 64 & $29 / 11 / 2013$ & $\begin{array}{l}\text { Regulamenta os procedimentos de acompanhamento e monitora- } \\
\text { mento da execução de ações complementares na atenção à saúde } \\
\text { dos povos indígenas. }\end{array}$ & Vigente \\
\hline $\mathrm{MS} / \mathrm{GM}$ & Portaria & 3.031 & $11 / 12 / 2013$ & $\begin{array}{l}\text { Institui Grupo de Trabalho para reavaliar o Incentivo de Atenção } \\
\text { Especializada aos Povos Indígenas. }\end{array}$ & Vigente \\
\hline$M S / G M$ & Portaria & 3.410 & $30 / 12 / 2013$ & $\begin{array}{l}\text { Estabelece as diretrizes para a contratualização de hospitais em } \\
\text { consonância com a Política Nacional de Atenção Hospitalar. }\end{array}$ & $\begin{array}{l}\text { Revogada pela Con- } \\
\text { solidação } n=2 / 2017\end{array}$ \\
\hline $\mathrm{MS} / \mathrm{CIT}$ & Resolução & 10 & $17 / 12 / 2013$ & $\begin{array}{l}\text { Garante a participação como Convidado de representantes da Saú- } \\
\text { de Indígena na Comissão Intergestores Regional e Bipartite. }\end{array}$ & Vigente \\
\hline $\begin{array}{l}\text { MS/ } \\
\text { Sesai }\end{array}$ & Portaria & 15 & $21 / 05 / 2014$ & $\begin{array}{l}\text { Regulamenta os procedimentos de acompanhamento e monitora- } \\
\text { mento da execução de ações complementares na atenção à saúde } \\
\text { dos povos indígenas. }\end{array}$ & Vigente \\
\hline $\begin{array}{l}\text { MS/ } \\
\text { Sesai }\end{array}$ & Portaria & 20 & $17 / 04 / 2015$ & Institui Grupo de Trabalho para discussão e revisão da PNASPI. & Vigente \\
\hline $\begin{array}{l}\text { MS/ } \\
\text { Sesai }\end{array}$ & Portaria & 21 & 28/04/2015 & Institui Grupo de Trabalho para discussão e revisão da PNASPI. & Vigente \\
\hline $\begin{array}{l}\text { MS/ } \\
\text { Sesai }\end{array}$ & Portaria & 51 & 26/08/2015 & Institui Grupo de Trabalho para discussão e revisão da PNASPI. & Vigente \\
\hline MS/GM & Portaria & 1.907 & $17 / 10 / 2016$ & $\begin{array}{l}\text { Revoga a Portaria no 475/2011, que estabelece a autonomia orça- } \\
\text { mentária do DSEI. }\end{array}$ & Não localizada \\
\hline$M S / G M$ & Portaria & 2.206 & $26 / 10 / 2016$ & $\begin{array}{l}\text { Revoga a Portaria no 2.141/2016, que estabelecia a delegação de } \\
\text { competência aos chefes do DSEI, inclusive quanto ao orçamento. }\end{array}$ & Vigente \\
\hline $\begin{array}{l}\text { MS/ } \\
\text { Sesai }\end{array}$ & Portaria & 22 & $16 / 02 / 2017$ & $\begin{array}{l}\text { Institui Grupo de Trabalho para elaborar proposta de alteração da } \\
\text { PNASPI. }\end{array}$ & Vigente \\
\hline $\mathrm{MS} / \mathrm{GM}$ & $\begin{array}{l}\text { Portaria de } \\
\text { Consolidação }\end{array}$ & 1 & 03/10/2017 & $\begin{array}{l}\text { Consolidação das normas sobre os direitos e deveres dos usuários } \\
\text { da saúde, a organização e o funcionamento do SUS. }\end{array}$ & Vigente \\
\hline$M S / G M$ & $\begin{array}{l}\text { Portaria de } \\
\text { Consolidação }\end{array}$ & 2 & 03/10/2017 & Consolidação das normas sobre as políticas nacionais de saúde. & Vigente \\
\hline $\mathrm{MS} / \mathrm{GM}$ & $\begin{array}{l}\text { Portaria de } \\
\text { Consolidação }\end{array}$ & 3 & 03/10/2017 & Consolidação das normas sobre as redes. & Vigente \\
\hline MS/GM & $\begin{array}{l}\text { Portaria de } \\
\text { Consolidação }\end{array}$ & 4 & 03/10/2017 & $\begin{array}{l}\text { Consolidação das normas sobre os sistemas e os subsistemas do } \\
\text { SUS. }\end{array}$ & Vigente \\
\hline MS/GM & $\begin{array}{l}\text { Portaria de } \\
\text { Consolidação }\end{array}$ & 5 & 03/10/2017 & $\begin{array}{l}\text { Consolidação das normas sobre as ações e os serviços de saúde do } \\
\text { SUS. }\end{array}$ & Vigente \\
\hline $\mathrm{MS} / \mathrm{GM}$ & $\begin{array}{l}\text { Portaria de } \\
\text { Consolidação }\end{array}$ & 6 & 03/10/2017 & $\begin{array}{l}\text { Consolidação das normas sobre o financiamento e a transferência } \\
\text { dos recursos federais para as ações e os serviços de saúde do SUS. }\end{array}$ & Vigente \\
\hline$M S / G M$ & Portaria & 2.663 & $11 / 10 / 2017$ & Redefinir os critérios para o repasse do IAE-PI. & Vigente \\
\hline
\end{tabular}

Fonte: Elaboração própria.

Os resultados indicam uma grande quantidade e diversidade de normas, que tratam de forma segregada o SUS e o Sasi, englobando diferentes temáticas. Isso dificulta para os cidadãos e autoridades públicas a compreensão e a execução da política de saúde indígena, podendo comprometer a plena garantia do direito à saúde desses povos ${ }^{17}$.

Um dos reflexos da segregação das normas é a ausência dos povos indígenas e do Sasi nos 
espaços de pactuação do SUS e, por consequência, nas suas legislações. A premissa da universalidade do acesso à saúde com integralidade e equidade, respeitando o relatório da VIII CNS, não foi suficiente para superar a fragmentação das ações do governo direcionadas aos povos originários, aqui evidenciada na fragmentação normativa, das pactuações e das relações institucionais. A estrutura de gestão, participação e controle do SUS e do Sasi está representada no quadro 2, demonstrando as singularidades dos espaços de participação social e as ausências de espaços de pactuações no Sasi.

Quadro 2. Instituições e instrumentos de gestão do Sistema Único de Saúde e Subsistema de Atenção à Saúde Indígena

\begin{tabular}{|c|c|c|c|c|c|c|c|}
\hline & \multicolumn{7}{|c|}{ SUS } \\
\hline & \multicolumn{2}{|c|}{ Nível Federal } & \multirow[t]{2}{*}{ Nível Estadual } & \multicolumn{3}{|c|}{ Nível Regional } & Nível Municipal \\
\hline & \multicolumn{2}{|r|}{ Sasi } & & & \multicolumn{2}{|l|}{ Sasi } & \\
\hline \multirow[t]{2}{*}{ Gestão } & \multicolumn{2}{|c|}{ Ministério da Saúde } & \multirow[t]{2}{*}{$\begin{array}{l}\text { Secretaria Estadual } \\
\text { de Saúde }\end{array}$} & & \multicolumn{2}{|c|}{$\begin{array}{l}\text { Secretaria Especial de Saúde } \\
\text { Indígena }\end{array}$} & $\begin{array}{l}\text { Secretaria Muni- } \\
\text { cipal de Saúde }\end{array}$ \\
\hline & \multicolumn{2}{|r|}{$\begin{array}{l}\text { Secretaria Especial } \\
\text { de Saúde Indígena }\end{array}$} & & & \multicolumn{2}{|c|}{$\begin{array}{l}\text { Distrito Sanitário Especial In- } \\
\text { dígena }\end{array}$} & \\
\hline $\begin{array}{l}\text { Instrumentos } \\
\text { de }\end{array}$ & $\begin{array}{l}\text { Plano Nacio- } \\
\text { nal de Saúde }\end{array}$ & $\begin{array}{l}\text { Plano Nacional de } \\
\text { Saúde }\end{array}$ & \multicolumn{2}{|l|}{$\begin{array}{l}\text { Plano Estadual de } \\
\text { Saúde }\end{array}$} & \multicolumn{2}{|c|}{$\begin{array}{l}\text { Plano Distrital de Saúde Indí- } \\
\text { gena }\end{array}$} & $\begin{array}{l}\text { Plano Municipal } \\
\text { de Saúde }\end{array}$ \\
\hline \multicolumn{8}{|l|}{ Planejamento } \\
\hline $\begin{array}{l}\text { Participação } \\
\text { Social }\end{array}$ & $\begin{array}{l}\text { Conselho } \\
\text { Nacional de } \\
\text { Saúde }\end{array}$ & $\begin{array}{l}\text { Fórum de Presi- } \\
\text { dentes de Condisi } \\
\text { Consultivo }\end{array}$ & \multicolumn{2}{|l|}{$\begin{array}{l}\text { Conselho Estadual de } \\
\text { Saúde }\end{array}$} & \multirow[t]{2}{*}{$\begin{array}{l}\text { Conselho } \\
\text { Distrital de } \\
\text { Saúde Indíge- } \\
\text { na (Condisi) }\end{array}$} & $\begin{array}{l}\text { Conselho Local } \\
\text { de Saúde Indí- } \\
\text { gena }\end{array}$ & $\begin{array}{l}\text { Conselho Muni- } \\
\text { cipal de Saúde }\end{array}$ \\
\hline $\begin{array}{l}\text { Instância de } \\
\text { Pactuação }\end{array}$ & \multicolumn{2}{|l|}{$\begin{array}{l}\text { Comissão } \\
\text { Intergestores } \\
\text { Tripartite }\end{array}$} & $\begin{array}{l}\text { Comissão Intergesto- } \\
\text { res Bipartite }\end{array}$ & \multirow[t]{4}{*}{$\begin{array}{l}\text { Comissão } \\
\text { Intergestores } \\
\text { Regional }\end{array}$} & & & \\
\hline Órgãos de & \multirow{2}{*}{\multicolumn{2}{|c|}{$\begin{array}{l}\text { Ministério Público Federal } \\
\text { Tribunal de Contas da União }\end{array}$}} & \multirow{3}{*}{$\begin{array}{l}\text { Ministério Público } \\
\text { Estadual } \\
\text { Tribunal de Contas } \\
\text { Estadual }\end{array}$} & & \multirow{3}{*}{\multicolumn{2}{|c|}{$\begin{array}{l}\text { Ministério Público Federal } \\
\text { Tribunal de Contas da União } \\
\text { Fundação Nacional do Índio }\end{array}$}} & \\
\hline \multirow[t]{2}{*}{ Controle } & & & & & & & \\
\hline & & $\begin{array}{l}\text { Fundação Nacio- } \\
\text { nal do Índio }\end{array}$ & & & & & \\
\hline
\end{tabular}

Fonte: Elaboração própria.

A fragmentação sempre esteve presente na história da assistência prestada pelo Estado aos povos originários. Ela não ocorre apenas na prática diária dos profissionais, mas, também, na história de disputas e divisões da responsabilidade de gestão entre as instituições - Fundação Nacional do Índio (Funai), Fundação Nacional de Saúde (Funasa) e Sesai -, e permeia todo o arcabouço legal, marcado por uma grande quantidade de normas que segmentam seus conteúdos ${ }^{\mathbf{1 7}}$.

No período de análise das legislações, identificam-se dois exemplos de esforço para consolidar as normativas, transformando-as em documentos únicos. O primeiro foi a publicação da Portaria no ${ }^{\circ} .048 / 2009$, que 'Aprova o Regulamento do SUS', consolidando as normas já publicadas, incluindo as Portarias $\mathrm{n}^{\circ} 70 / 2004, \mathrm{n}^{\circ} 399 / 2006, \mathrm{n}^{\circ} 2.656 / 2007$ e $\mathrm{n}^{\mathrm{o}}$ $2.759 / 2007$, relacionadas no quadro 1 , e revogando-as individualmente. Essa consolidação não entrou em vigor. Permaneceu em vacância legislativa até 05 de março de 2013. Nesse período, foi publicada a Portaria $\mathrm{n}^{\circ} 2.012 / 2012$, que alterou a Portaria no $2.656 / 2007$, extinguindo o Incentivo de Atenção Básica aos 
Povos Indígenas (IAB-PI), contudo, ao entrar em vigor, a Portaria ${ }^{\circ}$ 2.048/2009 não foi atualizada, trazendo novamente para a cena esse incentivo. O segundo exemplo trata da publicação de seis portarias de consolidação, em outubro de 2017, complexas e extensas, que revogam a Portaria $n^{0}$ 2.048/2009 e incorporam seu conteúdo.

Tais consolidações não superam a fragmentação das normas, pois não suplantam as diferenças de temporalidade e, tampouco, a lógica de constantes publicações normativas. Reforçam a dificuldade de compreensão e execução do sistema de saúde, podendo levar a uma descaracterização das políticas públicas específicas.

Importante considerar que políticas públicas estão em constante movimento e traçam uma trajetória única. Não são compostas por etapas lineares e claramente delimitadas, como: agenda, formulação, implementação e avaliação ${ }^{18}$. Analisando o conceito jurídico de política pública, Bucci'19 a define como 'programa de ação governamental que resulta de um processo ou conjunto de processos juridicamente regulados'. Como explica a autora,

[...] trata-se de abordagem institucional do processo governamental, baseada em pressuposto da tradição institucionalista da ciência política, segundo a qual as decisões e preferências são influenciadas ou distorcidas por regras e procedimentos. Uma vez que os processos contribuem para moldar as decisões, cabe trazê-los a lume de modo racional, compreendendo as formas pelas quais os próprios processos e seus pressupostos de formação tornam-se objeto de decisão, conscientemente informada de suas injunções políticas ${ }^{19(110-111) . ~}$

Para além da diversidade e da fragmentação das normas, a falta de definição clara, nessas legislações, dos papéis de cada instituição, confere maior complexidade à integralidade e à equidade em saúde, o que deveria ser garantido pelo Sasi. Dessa forma, a assistência à população indígena encontra-se fragilizada e à mercê das compreensões e ações individuais de cada gestor ao organizar a referência para a atenção especializada de forma distinta no território nacional. A indígena Tremembé (CE), em sua narrativa, nos faz refletir que a garantia da integralidade depende da posição política dos gestores com relação aos direitos indígenas:

Cada município é uma realidade diferente. Dos 184 municípios que tem no Ceará, que 18 tem indígenas. Se desses 18 tiver 5 que apoia o movimento indígena, é muito. Não apoia! E aí, por conta disso, dificulta mais as coisas, porque hoje a atenção básica ela funciona por conta das equipes que a gente tem pelo subsistema. Mas, se for ver pela questão da Média e Alta Complexidade, que já não é mais responsabilidade em si da Sesai... aí, acaba tudo!

A PNASPI destaca a rede de serviços de AB de saúde dentro das áreas indígenas sob gestão federal e estabelece estados e municípios como responsáveis pela complementariedade da assistência. $\mathrm{O}$ texto explicita a necessidade de garantir universalidade do acesso, integralidade da atenção à saúde com equidade. Aponta, ainda, para a diversidade de contextos na saúde indígena e para a importância de uma atenção diferenciada. Cecílio ${ }^{20}$ discute que esses princípios do SUS se constituem como um conceito tríplice na busca da saúde como um direito. $\mathrm{O}$ autor destaca que lutar por equidade e integralidade perpassa repensar a organização do processo de trabalho, a gestão e o planejamento e, nesse sentido, produzir novos saberes e práticas. Reconhece que esse processo é dependente, também, da escuta de cada profissional, para dar conta da integralidade ampliada e de contemplar a totalidade das demandas do usuário por uma melhor condição de vida, garantindo a potencialidade máxima de cada serviço de responder a todas elas ${ }^{20}$. Dessa forma, pode-se reforçar a importância da atenção diferenciada com processos de trabalhos distintos, que devem ser construídos conjuntamente com os povos indígenas em cada território. 
A gestão federal e o desafio da atenção diferenciada direcionada aos povos indígenas, que agrega a esta discussão a necessidade do compartilhamento das práticas tradicionais de cuidado em saúde, configuram um cenário único na implementação dessa política. A gestão federal, objeto de reivindicação nas CNSI e na IX CNS, é garantida na lei que institui o Sasi e foi reforçada nas Diretrizes da Gestão da PNASPI, Portaria $n^{\circ} 70 / 2004$. O Artigo $8^{\circ}$, ao tratar conjuntamente estados, municípios, instituições governamentais e não governamentais como complementares, devendo suas atribuições ser definidas no Plano Distrital de Saúde Indígena, mas sem especificá-las, fragiliza o papel institucional dos entes gestores do SUS. Isso reflete diretamente na ausência de discussão sobre os processos de trabalho nos espaços de gestão e atenção à saúde do SUS, o que interfere negativamente na garantia da assistência integral aos povos originários ${ }^{20}$.

Cabe ao gestor federal regulamentar a atuação complementar de estados e municípios na execução das ações de saúde aos povos indígenas, bem como as formas de acesso a essas ações. O não estabelecimento dos papéis de cada esfera de governo e suas inter-relações resultam na persistência, ao longo dos anos, da ausência de pactuação concreta e efetiva e, principalmente, em um descompromisso da maioria das gestões estaduais e municipais com a garantia de uma atenção diferenciada aos povos indígenas ${ }^{21}$.

Por outro lado, as ações centralizadas muitas vezes ocorrem, deixando os gestores municipais à margem do processo de gestão de aldeias que compõem o território municipal, como relatado pelo Gestor Municipal 1:

Um dia a secretária me liga. Ela tinha uma equipe do município que cuidava da saúde indígena, que ela que contratou. Chega lá um dia uma pessoa de uma OSS [Organização Social de Saúde] dizendo que eles iam assumir. Aí ela estranhou! Ela disse pra ele: '- Como? Eu sou responsável. Como é que você vai assumir?' [...] Aí, eu fui falar com o Secretário da Saúde Indígena, e ele falou: '- Olha, é isso mesmo! Eles ganharam a licitação'. Eu pensei: 'Pô, mas... Não poderia ter conversado?'.

Nesse sentido, reafirma-se a posição de Garnelo ${ }^{21}$ quanto ao abandono da noção de integralidade, a partir do momento que as ações se caracterizam mais pela fragmentação, com pouca interlocução com os demais órgãos e políticas sociais. Não contemplam questões fundamentais para a melhoria da condição de vida dos indígenas, como a segurança alimentar, articulação e valorização das medicinas indígenas, bem como a demarcação de terras.

A integralidade representa a expectativa de um sistema de saúde que rompa com a fragmentação da assistência. Mattos, na discussão sobre a prática da integralidade, aponta três campos de sentido: acesso universal e igualitário às ações e aos serviços de saúde; articulação entre assistência e prevenção; e uma compreensão ampliada da necessidade de ações de serviços de saúde ${ }^{22}$. Para além da integralidade, a descentralização é um princípio fundamental para a discussão da política de saúde. A descentralização caminha junto com a discussão do federalismo brasileiro. Arretche ${ }^{23(151)}$ define três dimensões da descentralização: política, fiscal e de competências. $\mathrm{E}$ afirma que a "descentralização fiscal e de competências não equivale à descentralização da autoridade decisória sobre a execução fiscal ou a provisão de políticas".

A falta de diálogo identificada entre as legislações que trazem as diretrizes e regulamentações do SUS com as legislações que tratam do Sasi reforça a necessidade de uma pactuação eficiente entre as três esferas de governo. A centralização da gestão no âmbito federal se contrapõe à diretriz constitucional de descentralização do SUS7 ${ }^{7}$ que visa a aproximar a gestão do sistema à realidade das pessoas, entrando em conflito com o processo de municipalização do SUS ${ }^{\mathbf{2 4}}$.

A garantia da integralidade no Sasi depende das redes municipal e estadual, conforme destacado por Garnelo ${ }^{21}$, o que reforça a necessidade de pactuações interfederativas. O Indigenista 2 
aponta essas relações como um grande gargalo que compromete a assistência à saúde:

Olha, o problema que existe, principal, é um grande vazio de pactuação. Primeiro porque o subsistema de saúde indígena é de atenção primária, que tem uma resolutividade muito baixa, de um modo geral. Então, não tem como prescindir da rede municipal e da rede estadual.

A descentralização do Sasi com a organização dos territórios do DSEI, que ultrapassam os limites de municípios e estados, é uma das principais justificativas para a centralização da gestão no âmbito federal, reforçada pelos constantes conflitos, inclusive com governos estaduais e municipais, nos processos de demarcações de terras indígenas ${ }^{\mathbf{1 4}}$. A entrevista com o Gestor Federal 1 reforça a importância desse território e o aponta como determinante nos avanços da saúde indígena:

A unidade territorial na saúde indígena ultrapassa as fronteiras municipais, muitas vezes os limites e divisas estaduais, conforma um território geográfico cultural muito específico que o município e o estado não dão conta. Então, essa ideia do distrito sanitário, com a responsabilidade federal sobre eles, acho que isso se consolidou, é decisivo. Eu acho que se o Ministério tivesse adotado uma política diferente dessa, a maior parte dos avanços que nós tivemos não teria sido obtido.

Essas instâncias regionais foram reivindicadas no relatório da II CNSI e foram estruturadas em função da diversidade de características de contato, culturais e de organizações políticas, sem preocupação em respeitar os limites entre municípios e estados, como destacou o Gestor Federal 1. Esse processo de distritalização foi se desenvolvendo com grande heterogeneidade de uma área para outra do País ${ }^{25}$. Contudo, a autonomia orçamentária e financeira prevista para os DSEI na CNSI, em 1993, começou a ser implantada em 2010, após a criação da Sesai10, com a publicação da Portaria no 475/2010.
Esse território tem a potência de impactar a integralidade ao configurar um espaço de governança estruturado no propósito de uma atenção diferenciada. Porém, a análise da legislação demonstra que essa descentralização da gestão e da execução das ações do Sasi não é uma discussão superada na gestão federal. A Portaria $\mathrm{n}^{0}$ 1.907/2016 retirou dos DSEI a autonomia orçamentária, o que resultou em grande mobilização dos povos indígenas que ocuparam o $\mathrm{MS}^{26}$. O MS, em resposta ao movimento \#OcupaSesai, publicou a Portaria ${ }^{\circ}$ 2.141/2016, que foi revogada pela Portaria ${ }^{\circ}$ 2.606/2016.

A entrevista com Gestor Municipal 1, em contraponto ao Gestor Federal 1, questiona essa lógica de gestão com a justificativa de que o MS não consegue dar conta das suas atribuições e que os indígenas residem nos territórios dos municípios:

[...] a população continua morando no município; então, criou-se uma situação meio difícil. E, assim, o Ministério também não tem condiçães. Então criou os DSEl, que também não dá muito conta, e o DSEI também não se articula muito com os municípios.

A análise da legislação demonstra que, no processo de implementação do SUS, foram elaboradas e divulgadas diversas Normas Operacionais Básicas (NOBs), sendo a NOB 01/93 a que trata da consolidação do poder municipal na gestão e execução das ações de saúde, com apoio técnico e financeiro dos poderes estaduais e federal, que são corresponsáveis por essa assistência. Para isso, trouxe as instâncias de pactuações estaduais, Comissão Intergestores Bipartite (CIB), que são compostas paritariamente pelo poder estadual e por representantes dos poderes municipais; e a instância Nacional, Comissão Intergestores Tripartite (CIT), composta paritariamente por representantes dos poderes federal, estaduais e municipais, conforme apresentadas no quadro 2. Essas instâncias são responsáveis por, em consenso, pactuar a organização da assistência à saúde nas suas regiões ${ }^{27}$. 
O processo de criação de regiões de saúde, como uma estratégia de regionalização, foi discutido na Norma Operacional da Assistência à Saúde (Noas) em 2001 e retomado em 2006 pelo Pacto pela Saúde. As diretrizes desse pacto reafirmam a sua importância e de instrumentos de planejamento e programação, além de instituir os Colegiados de Gestão Regional (CGR) ${ }^{\mathbf{2 8}}$. Assim, explicita a necessidade de pactuações e articulação das diversas esferas de gestão. Considerada um avanço na implementação do SUS, essa normativa trouxe destaque para diferentes áreas e grupos populacionais, entretanto, mesmo com um número acumulado de publicações de normas referentes ao Sasi, incluindo a PNASPI, a análise dos resultados demonstra que a saúde indígena permaneceu invisibilizada.

O Decreto $\mathrm{n}^{0} 7.508 / 2011$ instituiu as Comissões Intergestores Regionais (CIR), que substituem os CGR, com atribuições semelhantes à CIB no seu território de governabilidade. $\mathrm{O}$ artigo 32 desse Decreto estabelece que essas CIRs pactuarão sobre a assistência na região. Mesmo o Decreto reconhecendo o direito dos indígenas a regramentos de acesso diferenciados, reforçando a importância da regionalização para a organização dos SUS, a relação Interfederativa nas CIR, CIB e CIT, e estabelecendo que o Contrato Organizativo de Ações Públicas, instrumento de formalização da pactuação regional, fosse assinado pelos três entes federados, não trata sobre a participação do gestor federal ou de representantes dos DSEI nas CIR e CIB.

A importância da participação da gestão da saúde indígena nas instâncias formais de pactuação do SUS foi objeto de discussão, como destacaram alguns entrevistados, e culminou na assinatura, em plenária da $\mathrm{V}$ CNSI, em 2013, da Resolução CIT 10/2013, que autoriza a participação de representantes da gestão do Sasi como convidados nas reuniões de CIR e CIB. A inserção dos representantes do Sasi nessas instâncias de pactuação traz reflexões, em alguns locais, quanto à presença do terceiro ente federado e, em outros, quanto à falta do poder concreto de fala e de voto nas deliberações.

As entrevistas retrataram a ausência dessa discussão nas instâncias de pactuação, o que resulta, associado à falta de clareza dos papéis institucionais, em grande fragilidade da relação interfederativa nessa política, como demonstra a entrevista do Gestor Municipal 1:

A CIR, então, o DSEI tem que participar. No Norte, além da Secretaria Estadual de Saúde, que coordena junto com os municípios e os representantes dos gestores municipais, tinham que participar os DSEl também. [...] mas não é como convidado. Isso já foi um erro, ele é participante mesmo. Porque ele é responsável pela Constituição, e eu não posso! Se sou gestor municipal, eu não posso interferir se eu não for solicitado.

Porém, o Gestor Municipal 2 entende que essa presença seria positiva, mas ressalta a importância de construir uma relação com o município que possui aldeia, e não diretamente com a CIR:

Agora, veja, acho que tem um passo anterior. Do jeito que nós estamos estruturados, o passo anterior é construir essa ponte no próprio município. Acho difícil construir essa ponte na CIR sem que você tenha construído previamente no município. Eu diria mais! Eu acho que deveria ser uma demanda, inclusive, do próprio município, o município [...]. Porque, veja, eu acho que fica muito exótico você chegar na CIR sem ter essa ponte prévia com o município. Eu acho que fica esquisito, entendeu?

A CIR e a CIB deveriam ser espaços onde essa discussão do papel de cada instância de gestão também estivesse colocada, mas a garantia de participação de representantes da saúde indígena, apenas a partir de 2013, faz com que essas instâncias, de forma geral, estejam distantes dessa discussão, conforme é reconhecido na fala do Gestor Estadual 1 ao referir-se à CIB: 
Nós não temos feito nenhum debate organizado nesse tema, e nas Secretarias Estaduais isso acaba acontecendo de uma maneira diferenciada a partir da realidade de cada secretaria e como cada secretaria se relaciona com o Cosems [Conselho de Secretarias Municipais de Saúde] e com as representações da Sesai.

A falta de participação nessas instâncias de pactuação faz emergirem questões quanto à autonomia de gestão política dos DSEI nos territórios e à especialização e à operacionalização das pautas dessas instâncias, que muitas vezes não dialogam com as necessidades dos territórios indígenas.

É importante destacar que gestores federais também compreendem a falta de discussão da saúde indígena nos espaços de pactuação, com uma percepção de um problema estrutural da organização do SUS, principalmente no que se refere à estrutura do financiamento. Refletem sobre a articulação com o Conselho Nacional de Secretários de Saúde (Conass) e o Conselho Nacional de Secretarias Municipais de Saúde (Conasems), que ganham repercussão na discussão de propostas de incentivos financeiros, mas de forma muito isolada quando se pretende discutir a produção de saúde de grupos populacionais que não são comuns a todos os municípios, como chama atenção o Gestor Federal 2:

[...] toda vez que envolve populações vulneráveis onde a agenda não é comum, é muito difícil produzir na lógica de organização dos Secretários Municipais de Saúde um processo de discussão, de construção de proposta, de enfrentamento de interesses do Estado, do Ministério da Saúde e tal, pra poder colocar essa agenda de maneira mais forte.

As entrevistas apontaram que há distintos motivos entre indígenas e gestores que interferem nessas pactuações. O poder garantido ao ente que é responsável pela execução do recurso, considerando se tratar de uma quantia financeira significativa de grande capilaridade no território brasileiro federal, é um ponto importante para os gestores. Além disso, há atravessamentos políticos no cotidiano dos territórios indígenas que levam a um distanciamento de estados e municípios. Isso faz com que a gestão do subsistema ganhe destaque para além da discussão do cuidado com a saúde, como afirma o Indigenista 2:

Então, essa ausência de debate, de diálogo com os municípios, ela é muito mais prejudicial do que protetiva, e as razões são completamente distintas. Os índios não querem os diálogos, muitas vezes por razões políticas, mas o governo federal não quero diálogo por outras razões, porque quer centralizar os recursos e deliberar sozinho. E ficar, digamos assim, fora de um certo controle que Cosems e Conasems fazem a respeito da gestão dos recursos.

Nesse processo, várias iniciativas de maneira desarticulada ocorreram em todos os âmbitos. A análise das legislações apontou que, entre 2015 e 2017, foram publicadas quatro portarias compondo o Grupo de Trabalho (GT) para discussão e revisão da PNASPI - todas encontravam-se vigentes em maio de 2018 no banco de dados Saúde Legis. Conass e Conasems estavam ausentes e foram incluídas na primeira republicação. Da mesma forma, a elaboração da Nota Técnica 04 pelo Conass, em 2014, denominada 'A integração da saúde indígena no SUS: uma proposta da gestão estadual', sem atuação da Sesai ou de representantes do movimento indígena, foi criticada ${ }^{29}$.

As ausências dos povos indígenas e seus modos de vida estão marcadas na legislação. Essas normativas, que não possibilitam a execução de uma política pública nos diferenciados contextos do País, retratam uma legislação que não promove a justiça social. Garantir acesso universal, integralidade do cuidado e equidade vai muito além da publicação de políticas afirmativas. Demanda uma ação ativa do Estado, que deve dialogar com a população. Faz-se necessário proatividade de todas as esferas de gestão na garantia do direito constitucional de todo cidadão à saúde, que só 
ocorrerá com as superações de macrodisputas colocadas, como a demarcação de terras, o colonialismo interno, que é estrutural no Estado brasileiro, bem como a municipalização da gestão do Sasi.

A garantia de visibilidade e existência dos povos indígenas na política de saúde não é conquistada automaticamente pela criação do Sasi e aprovação da PNASPI. É preciso enfrentar a supremacia da biomedicina, do modo de vida capitalista e a fragmentação estatal para preservar o direito à saúde. Assim, é preciso efetivar essa política, garantindo a existência de espaços vivos de participação que permitam a discussão do pluralismo médico existente no território para a construção da atenção diferenciada, respeitando os modos de vida dos mais de 300 povos, como destaca a entrevista de Guajajara (MA):

Porque existe uma Política Nacional de Saúde e existe a Política Diferenciada para trabalhar com a gente, mas esta política está muito no papel. A implementação requer um olhar nosso, uma fala nossa, um costume nosso, tá entendendo? Um respeito maior nosso. Eu vejo que é o que falta.

\section{Considerações finais}

A partir da CF, a consolidação do SUS e a conquista de uma assistência à saúde para os povos indígenas não caminharam, necessariamente, lado a lado. Com legislações específicas, os processos trilhados pelo Sasi parecem sempre correr atrás das diretrizes específicas do SUS em busca de reconhecimento, como na discussão da participação de representantes da saúde indígena em CIR e CIB. É importante ressaltar que SUS e Sasi não são sistemas de saúde distintos. O Sasi compõe o SUS, com um papel específico e diferenciado. Entretanto, a generalidade do SUS nem sempre abriu espaço para as especificidades do Sasi.

Os resultados apontam para uma importante fragilidade no que se refere à organização normativa da saúde indígena no Brasil, como: a não objetividade das responsabilizações institucionais e a falta de discussão quanto à participação nos espaços de pactuação. Pode-se constatar que poucos foram os avanços após a publicação da PNASPI no âmbito da regulamentação do subsistema.

Nesse contexto de vulnerabilidade jurídica e social, os mais de 300 povos indígenas do território brasileiro vêm sofrendo sucessivas tentativas de retrocessos no que se refere à garantia dos seus direitos constitucionais. Exemplos disso são as tentativas de alterar a gestão do Sasi, com a retirada da autonomia orçamentária dos DSEI e o Projeto de Emenda Constitucional (PEC) 215/2000, que tramita no Congresso e altera o processo de demarcação das terras indígenas, transferindo essa responsabilidade para o Congresso Federal.

É importante ressaltar a especificidade da saúde indígena no que tange à sua organização territorial e assistencial. $\mathrm{O}$ respeito às deliberações das CNSI e IX CNS, que indicam a gestão direta do Sasi pelo governo federal, deve ser garantido. Do mesmo modo, a territorialização dos DSEI precisa ser soberana com relação aos processos de municipalização, cabendo aos entes federados a superação dos desafios colocados na articulação interfederativa, contribuindo para a integralidade no SUS.

Garantir aos povos indígenas o direito à saúde, respeitando-se os princípios constitucionais da universalidade, integralidade e equidade, é uma tarefa que exige, ainda, a superação de muitos desafios e a definição de avanços e compromissos claros e objetivos por parte dos entes federativos.

Superar os paradoxos do SUS e do Sasi de maneira responsável e compartilhada entre gestores e indígenas requer ousadia e determinação na produção de políticas públicas de direito à saúde. Exige, principalmente, a compreensão de que terra é saúde, e, portanto, a discussão da demarcação de terras não pode estar apartada desse processo político. Este artigo abordou um dos pontos que compõem esse complexo universo, 
desvelando e analisando de forma sistemática o arcabouço jurídico-institucional do Estado brasileiro para a garantia do direito à saúde dos povos originários, como um ponto de partida para análises e debates que contribuam para a efetivação da política de saúde.

\section{Colaboradores}

Scalco N (0000-0001-6374-8145)*, Aith F (0000-0003-1971-9130)* e Louvison M (00000003-1630-3463)* contribuíram igualmente para a elaboração do manuscrito.

\section{Referências}

1. Instituto Brasileiro de Geografia e Estatística. Estudos Especiais: O Brasil Indígena - Língua falada [internet]. Brasília, DF: IBGE; [acesso em 2017 abr 23]. Disponível em: http://indigenas.ibge.gov.br/estudos-especiais-3/o-brasil-indigena/lingua-falada.

2. Brasil. Constituição, 1988. Constituição da República Federativa do Brasil. Brasília, DF: Senado Federal; 1988.

3. Garnelo L. O SUS e a Saúde Indígenas: matrizes políticas e institucionais do Subsistema de Saúde Indígena. In: Teixeira CC, Garnelo L, organizadoras. Saúde Indígena em perspectiva: explorando suas matrizes históricas e ideológicas. Rio de Janeiro: Fiocruz; 2014. p. 107-144.

4. Brasil. Ministério da Saúde. Relatório da $1^{\text {a }}$ Conferência Nacional de Saúde Indígena [internet]. Brasília, DF: MS; 1986 [acesso em 2014 abr 25]. Disponível em: http://portalsaude.saude.gov.br/index.php/ oministerio/principal/secretarias/secretaria-sesai.

5. Brasil. Ministério da Saúde. Relatório da $2^{\mathrm{a}}$ Conferência Nacional de Saúde para os Povos Indígenas [internet]. Luziânia: MS; 1993 [acesso em 2014 abr 25]. Disponível em: http://189.28.128.100/dab/docs/ geral/2cnsi.pdf.

6. Brasil. Ministério da Saúde. Lei nº 8080, de 19 de setembro de 1990. Dispõe sobre as condições para pro- moção, proteção e recuperação da saúde, a organização e o funcionamento dos serviços correspondentes e dá outras providências. Diário Oficial da União. 20 Set 1990.

7. Abrucio FL, Franzese C. Federalismo e Políticas Públicas: o impacto das relações intergovenamentais no Brasil. In: Araújo MF, Beira L, organizadores. Tópicos de economia paulista para gestores públicos. São Paulo: Fundap; 2007. p. 13-31.

8. Brasil. Lei ${ }^{0}$ 8142, de 28 de dezembro de 1990. Dispõe sobre a participação da comunidade na gestão do Sistema Único de Saúde - SUS e sobre as transferências intergovernamentais de recursos financeiros na área de saúde e dá outras providências. Diário Oficial da União. 31 Dez 1990.

9. Fundação Nacional de Saúde. Política Nacional de Atenção à Saúde dos Povos Indígenas. Brasília, DF: MS; Funasa; 2002.

10. Cardoso MD. Políticas de saúde no Brasil: do modelo assistencial à representação política. In: Langdon EJ, Cardoso MD, organizadoras. Saúde Indígena: Políticas Comparadas na América Latina. Florianópolis: UFSC; 2015. p. 83-106.

11. Santos BS. Reconhecer para libertar: os caminhos do cosmopolitismo multicultural. Rio de Janeiro: Civilização Brasileira; 2003.
${ }^{\star}$ Orcid (Open Researcher and Contributor ID). 
12. Albrecht CAM, Rosa RS, Bordin R. O conceito de equidade na produção científica em saúde: uma revisão. Saúde Soc. 2017; 26(1):115-128.

13. Santos BS, Chauí M. Direitos humanos, democracia e desenvolvimento. São Paulo: Cortez; 2013.

14. Tauli-Corpuz V. Relatório da missão ao Brasil da Relatora Especial sobre os direitos dos povos indígenas [internet]. Genebra: Conselho de Direitos Humanos das Nações Unidas; 2016 [acesso em 2018 fev 18]. Disponível em: http://unsr.vtaulicorpuz.org/site/images/ docs/country/2016-brazil-a-hrc-33-42-add-1-portugues.pdf.

15. União das Nações Indígenas. Os povos indígenas e o direito à saúde. Saúde debate. 1988; (nº especial):8-9.

16. Minayo MCS. O desafio do conhecimento: pesquisa qualitativa em saúde. 13. ed. São Paulo: Hucitec; 2013.

17. Aith F. Saúde indígena no Brasil: atual quadro jurídico-administrativo do estado brasileiro e desafios para a garantia do direito à saúde da população indígena. Rev. direito sanit. 2008; 9(3):115-132.

18. Rezende M, Baptista TWF. A Análise da Política proposta por Ball. In: Mattos RA, Baptista TWF, organizadores. Caminhos para Análise das Políticas de Saúde. Porto Alegre: Rede UNIDA; 2011. p. 173-180.

19. Bucci MPD. Fundamentos para uma Teoria Jurídica de Políticas Públicas. São Paulo: Saraiva; 2013.

20. Cecílio LCO. As necessidades de saúde como conceito estruturante na luta pela integralidade e equidade na atenção à saúde. In: Pinheiro R, Mattos RA, organizadores. Os sentidos da integralidade na atenção e no cuidado à saúde. Rio de Janeiro: IMS/Uerj/Abrasco; 2001. p. 113-126.

21. Garnelo L. Política de Saúde dos Povos Indígenas no Brasil: Análise Situacional do Período de 1990 a 2004 [internet]. Porto Velho: Cesir/UFRR; 2004 [acesso em 2018 dez 13]. Disponível em: http://www.cesir. unir.br/pdfs/doc9.pdf.
22. Mattos RA. A integralidade na prática (ou sobre a prática da integralidade). Cad. Saúde Pública. 2004; 20(5):1411-1416.

23. Arretche M. Democracia, federalismo e centralização no Brasil. Rio de Janeiro: FGV; Fiocruz; 2012.

24. Barata LRB, Tanaka OY, Mendes JDV. Por um processo de descentralização que consolide os princípios do Sistema Único de Saúde. Epidemiol. Serv. Saúde. 2004; 13(1):15-24.

25. Athias R, Machado MA. Saúde indígena no processo de implantação dos Distritos Sanitários: temas críticos e propostas para um diálogo interdisciplinar. Cad. Saúde Pública. 2001; 17(2):425-431.

26. Articulação dos Povos Indígenas do Brasil. Mobilização Nacional Indígena. Brasília [internet]. Brasília, DF: Apib; 2016 [acesso em 2018 set 9]. Disponível em: https://mobilizacaonacionalindigena.wordpress. com/2016/10/.

27. Brasil. Ministério da Saúde. Portaria $\mathrm{n}^{0} 545$, de 20 de maio de 1993. Estabelece normas e procedimentos reguladores do processo de descentralização da gestão das ações e serviços de saúde, através da Norma Operacional Básica - SUS 01/93. Diário Oficial da União. 24 Maio 1993.

28. Brasil. Ministério da Saúde. Portaria n ${ }^{\circ} 399$, de 22 de fevereiro de 2006. Divulga o Pacto pela Saúde 2006 - consolidação do SUS e aprova as diretrizes operacionais do referido pacto. Diário Oficial da União. 23 Fev 2006.

29. Conselho Nacional de Secretários de Saúde. Nota Técnica 04 [internet]. Brasília, DF: Conass; 2014 [acesso em 2018 nov 18]. Disponível em: http://www. conass.org.br/wp-content/uploads/2014/04/NT-04-2014-SAU\%CC\%81DE-INDIGENA.pdf.

\footnotetext{
Recebido em 07/11/2019

Aprovado em 06/08/2020

Conflito de interesses: inexistente

Suporte financeiro: Capes - Coordenação de Aperfeiçoamento de Pessoal de Nível Superior - Código de Financiamento 001
} 